\title{
Exploring the connection between community food security initiatives and social-cognitive factors on dietary intake
}

\author{
Diana Cuy Castellanos, ${ }^{*}$ Josh Keller, ${ }^{\mathrm{b}}$ and Emma Majchrzak ${ }^{\mathrm{c}}$ \\ University of Dayton, Department of Health and Sport Science
}

Submitted September 9, 2015 / Revised October 29 and December 11, 2015, and August 29, 2016 /

Accepted August 29, 2016 / Published online November 23, 2016

Citation: Cuy Castellanos, D.., Keller, J., \& Majchrzak, E. (2016). Exploring the connection

between community food security initiatives and social-cognitive factors on dietary intake.

Journal of Agriculture, Food Systems, and Community Development, 7(1), 21-31.

http://dx.doi.org/10.5304/jafscd.2016.071.006

Copyright (C) 2016 by New Leaf Associates, Inc.

\begin{abstract}
Food insecurity and poor dietary consumption continues to impact low-income populations in the U.S. However, communities are developing ways to address it at the local level. Community Food Security Initiatives (CFSI) focus on increasing a sustainable, healthy food supply and food system while simultaneously addressing food insecurity and dietary quality within a community. The
\end{abstract}

a * Corresponding author: Diana Cuy Castellanos, Department of Health and Sport Science, University of Dayton; 646 Fitz Hall, 300 College Park Avenue; Dayton, Ohio 45469 USA; +1-937229-4206; dcuycastellanos1@udayton.edu

b Josh Keller, Department of Health and Sport Science, University of Dayton; 646 Fitz Hall, 300 College Park; Dayton, Ohio 45469 USA; kellerj9@,udayton.edu

${ }^{c}$ Emma Majchrzak, Department of Health and Sport Science, University of Dayton; Corbly Hall, One John Marshall Drive; Huntington, West Virginia 25755 USA; emmajchrzak@yahoo.com purpose of this study was two-fold: (1) explore CFSIs in low-income areas in a metropolitan Midwest city and (2) examine the effects of the initiatives along with other social-cognitive factors on fruit and vegetable consumption in persons participating in local CFSIs. This was a mixed methods study. First, seven representatives from different CFSIs were interviewed and factors regarding initiative success were identified. Secondly, a group of 128 community members made up of both CFSI participants and non-CFSI participants completed questionnaires assessing

\section{Author's note}

This study was financially supported by an internal research seed grant from the University of Dayton. There are no conflicts of interest to disclose. Portions of the research presented in this article were presented at the Society of Nutrition Education and Behavior conference in Pittsburgh, Pennsylvania, in July 2015, and at the Nutrition and Food Conference and Exhibition in Nashville, Tennessee, in October 2015. 
fruit and vegetable intake, dietary-related social cognitive behavior, and socio-demographics. Several themes emerged from the interviews with the CFSI representatives including challenges, resources, and benefits in developing and sustaining an initiative. A multiple regression analysis was utilized to explain fruit and vegetable behavior across CFSI participation and dietaryrelated social-cognitive factors, controlling for education and income. The analysis showed that dietary-related social-cognitive factors, not CFSI participation, were an independent predictor of fruit and vegetable intake. In conclusion, CFSIs may increase food access within a local food system but may have a minimal impact on dietary behavior overall. CFSIs may need to reexamine their operations and identify ways to address not only food access but other social factors such as community empowerment and individual psychosocial factors relating to dietary behavior.

\section{Keywords}

Community Food Security Initiatives; SocialCognitive; Dietary Quality; Fruit And Vegetable Intake

\section{Introduction and Literature Review}

Over the past 20 years, the alternative or local food movement has grown significantly (Low et al., 2015). The movement encourages people to consume foods produced within a "local" area and promotes sustainable growing practices, local economic growth, social equity, and healthy food consumption. Contrary to this purpose, however, the movement has been criticized for cultivating social inequality. For instance, Mares and Alkon (2011) commented that "critics have highlighted issues of inequality, examining the social, political, and cultural processes that determine who is drawn to and has the ability to produce and consume particular kinds of food" (p. 69). Participants of the movement within the U.S. have tended to be white and middle-to-upper class, not reaching the parts of society that confront low food access and poor dietary quality (Low et al., 2015). For instance, people of middle-to-upper classes have higher dietary quality and are less likely to be overweight or obese when compared to low-income populations (Colasanti, Conner, \& Smalley, 2010;Ogden, Carroll, Kit, \& Flegal, 2014; Racine, Mumford, Laditka, \& Lowe, 2013). For example, low-income populations in the U.S. have lower intakes of fresh fruits and vegetables and higher intakes of processed foods compared to the daily requirements (Leung, Ding, Catalano, Willamor, Rimm, \& Willet, 2012). Therefore, in order to promote not only food security but also dietary quality within low-income populations, it is crucial to ensure food access and address negative dietary behaviors.

Recently, to address this concern, community food security initiatives (CFSIs) emerged and have been attempting to close the gap between socioeconomic status, food access, and dietary quality by increasing access to a sustainable and healthy food supply through the use of multiple local sectors (Low et al., 2015). Over the past two decades, CFSIs have been utilized to combine aspects of the local food movement with an anti-food-insecurity approach. (Kaiser, 2011; United States Department of Agriculture [USDA], 2015). They do so by "arguing that all communities should have access to safe, culturally acceptable, nutritionally adequate, and sustainably produced diets" (Mares \& Alkon, 2011, p. 69). The initiatives are attractive to community coordinators and leaders not just because of their potential to improve the diet and health of local citizens, but also because of their potential to improve the social and economic state of the community as a whole (Kaiser, 2011).

However, though many of the programs and initiatives are attempting to address food security and dietary quality primarily by targeting food access, they may be falling short. The factors that influence dietary intake are vast and include a complex interplay between environmental and social factors (Caswell \& Yaktine, 2013). Many CFSIs may be too simplistic in their efforts by targeting only food access. For example, recent research suggests that distance to the supermarket, residing in a food desert, or increasing supermarket access may not impact dietary intake in low-income populations as much as previously thought (Budzynska et al., 2013; Cummins, Flint, \& Matthews, 2014; Dubowitz, Zenk, et al., 2015; Hackett et al., 2012; Pearson, Russell, Campbell, \& Barker, 2005). Caspi, 
Kawachi, Subramanian, Adamkiewicz, and Sorenson (2012) found that perception of access to a supermarket influenced dietary intake more than actual access.

Furthermore, many social factors contribute to dietary behavior beyond having certain foods available. For instance, psychosocial constructs such as perceived barriers, nutrition knowledge, cooking skill, attitudes, motivation, behaviors, social support, and self-efficacy have all been shown to affect dietary intake (Aggarwal, Monsivais, Cook, \& Drewnowski, 2014; Dubowitz, Cohen, Huang, Beckman, \& Collins, 2015; Flórez, Dubowitz, Ghost-Dastidar, Beckman, \& Collins, 2015). For example, Pearson et al. (2005) found food access did not correlate with intake, but socio-cultural attitudes did.

Moreover, researchers have argued CFSIs fail to encourage and promote ownership within the community as well as address cultural and social factors related to dietary intake, therefore limiting their effect on dietary behavior (Mares \& Alkon, 2011; Pearson et al., 2005; Ver Ploeg, \& Rahkovsky, 2016). They suggest that often, CFSIs do not cultivate community empowerment because they lack the voice of the community within the initiative's leadership. As a result, decision-making does not occur at the community level.

In this study, two questions were examined in terms of CFSIs and their effectiveness in promoting a healthy diet within the community where they work and serve. First, did an increase in access to healthy foods lead to an increase in dietary quality within the population? Secondly, how important was it to target social factors related to dietary intake in low-income communities?

In this study, we explored the interplay between local CFSIs and social-cognitive factors in relation to fruit and vegetable consumption in a sample of people residing in low-income areas within the metropolitan city of Dayton, Ohio. First, we interviewed key informants from seven different local initiatives to gain insight regarding their mission and purpose. Then, we administered questionnaires to people residing in low-income areas of Dayton where the identified CSFIs were located in order to examine fruit and vegetable intake, participation in a CFSI, dietary-related social-cognitive factors, and their relation to each other. The dietary-related social-cognitive factors included the following constructs: intention, selfefficacy, social support, outcome expectancies, outcome expectations, behavioral strategies, and situational setting. We wanted to examine if promoting access to healthy food in a low-income population was sufficient to address dietary quality or if other influencing factors needed to be considered. We did not measure food security although we did target low-income populations in the area.

This research took place in Dayton, Ohio, a metropolitan city. In 2015, there were 140,599 residents within the city limits with $35.3 \%$ living below the poverty line (US Census Bureau, 2016). In terms of race, of all residents in Dayton, Ohio, $51.1 \%$ were White and $42.9 \%$ Black. In 2015, Dayton was ranked eleventh in the country by the Food Action and Research Center for experiencing food hardship (Rosso, 2016).

\section{Applied Research Methods}

There were two phases of this study. In phase 1, semistructured interviews were administered to representatives from CFSIs. In phase 2, dietary behavior, fruit and vegetable intake, and CFSI participation were examined. The study was approved by the University of Dayton Institutional Review Board.

\section{Phase 1: Key Informant Interviews from CFSIs}

In phase 1, the research team (consisting of the lead researcher and two research assistants) identified the ten zip codes in Dayton with the lowest household income. CFSIs were identified through an internet search and through conversations with local key informants (Table 1). The research team contacted a representative from each initiative requesting a semistructured interview. The purpose of the interviews was to explore the aims of each initiative and the ways that they tried to achieve their respective aims.

Grounded theory qualitative methodology guided data collection and analysis. The lead researcher administered and audio-recorded each semistructured interview. The research team developed a semistructured interview guide that 
included questions regarding to the development and implementation procedures of the CFSI, current proceedings, and initiative goals, objectives, resources, weaknesses, strengths, and future plans. The interviews were transcribed verbatim and analyzed using open, axial, and selective coding (Hoepfl, 1997). The coding process began simultaneously with data collection.

The coding process occurred through the following procedures. All coders analyzed the same three transcriptions using line-by-line coding. The coders discussed the identified and defined codes, leading to the development of a codebook. The codebook included core codes identified by the coders. Codes that were not agreed upon were discussed until an agreement was reached. Axial coding proceeded the line-by-line coding. During this process, the team began to identify where codes converged, thus revealing core themes; constant comparison was employed to examine the data across transcriptions and coders. Finally, during selective coding and based on the themes identified previously, the research team identified main categories, leading to the development of a conceptual framework of community food security initiatives in low-income areas.
Phase 2: Community Member Participation in CFSIs and Effect on Fruit and Vegetable Intake

In the second phase, the research team examined and compared factors effecting fruit and vegetable consumption in two different participant groups: (1) community members who were part of and/or purchased or obtained food from an identified CFSI in a low-income area (farmers market, CSA, community garden, local food stand, or food bank distributing fresh produce), and (2) community members who lived in areas where the identified CFSIs were located but who did not participate. For example, a CSA member from the urban farm identified in phase 1 was considered a CFSI participant, but their neighbor who was not a CSA member and did not participate in any CFSI (purchase foods at the local farmers market, participate in a community garden, etc....) was considered a non-CFSI participant for this study. Participants were recruited from the local community food security initiatives and at local community events. Community events included a health fair, an after school program, and a parenting program. These events were chosen because each took place within one of the ten targeted low-income areas identified in phase 1.

Table 1. The Type of Community Security Food Initiative Represented in the Key Informant Interviews

\begin{tabular}{|c|c|c|}
\hline $\begin{array}{l}\text { Key Informant } \\
\text { No. }\end{array}$ & Community Security Food Initiative type & Activities \\
\hline 1 & $\begin{array}{l}\text { Urban farm in East Dayton in a low-income area. } \\
\text { The farm has a farm stand and a CSA and } \\
\text { accepts Electronic Benefit Transfers (EBT). }\end{array}$ & $\begin{array}{l}\text { Farm three urban plots and have } 40 \text { families in their } \\
\text { CSA. }\end{array}$ \\
\hline 2 & $\begin{array}{l}\text { Healthcare community garden serving a diverse } \\
\text { population in a low-income suburb of Dayton, } \\
\text { Ohio. }\end{array}$ & 15 plots gardened by local families. \\
\hline 3 & Community garden in downtown Dayton & 10 plots gardened by local residents. \\
\hline 4 & $\begin{array}{l}\text { The local food bank. The food bank accepts } \\
\text { donations from public and private entities and } \\
\text { has a garden. }\end{array}$ & $\begin{array}{l}\text { Serves more than } 80 \text { food pantries in the area and } \\
\text { runs a mobile distribution pantry. The food bank was } \\
\text { beginning a garden to produce food where distribution } \\
\text { research was conducted. }\end{array}$ \\
\hline 5 & $\begin{array}{l}\text { Community healthcare clinic for low-income } \\
\text { clients. The clinic includes medical, dental, } \\
\text { and dietary services as well as a food bank } \\
\text { and garden. }\end{array}$ & Serves approximately 2500 people each year. \\
\hline 6 & Farmers market accepting EBT. & $\begin{array}{l}\text { Saturday-only market. This was the only farmers market } \\
\text { in Dayton that accepted EBT during time of this } \\
\text { research. }\end{array}$ \\
\hline 7 & $\begin{array}{l}\text { A local elementary school starting a school } \\
\text { garden. }\end{array}$ & $\begin{array}{l}\text { The school serves approximately } 500 \text { students and has } \\
\text { a high Turkish and Hispanic immigrant population. }\end{array}$ \\
\hline
\end{tabular}


Each participant was over eighteen years of age.

The purpose of this phase was to examine how participation in CFSIs as well as other dietaryrelated social-cognitive factors (defined in Table 2) affected fruit and vegetable intake. The researcher team's intention was to use the findings of phase 1 and phase 2 to draw conclusions and identify gaps in how we, as a collaborative society, are addressing healthy dietary intake in low-income populations within metropolitan settings. In this study, healthy dietary intake is measured by fruit and vegetable intake.

\section{Instruments}

Participants of the study completed Eating at America's Table Quick Food Scan (QFS) developed by the National Institutes of Health (Thompson et al., 2002), a social-cognitive dietary questionnaire (SCDQ) (Dewar, Lubans, Morgan, \& Plotnikoff, 2013), and a socio-demographic questionnaire. The QFS is a nine food-item screener and can be used to estimate daily fruit and vegetable serving consumption. The screener was scored using the outlined protocol for the instrument (National Cancer Institute, 2013). The SCDQ was originally developed to examine seven constructs (see Table 2) relating to adolescent healthy eating behavior: self-efficacy, intentions, situation, behavioral strategies, social support, outcome expectations, and outcome expectancies. The questionnaire was tested on, and deemed reliable and valid for, the adolescent population (Dewar et al., 2013). For the present study, Cronbach alpha correlation coefficients were employed to assess internal consistency within the study population. Each subscale showed adequate internal consistency (>.70). For scoring, each scale was scored on a continuum and contained four to seven items with four to six response choices. Some of the items were reverse coded. For each scale, a higher score insinuated a greater psychosocial level for the construct. For example, the higher a person's selfefficacy score, the more self-efficacy the person possessed in terms of healthy eating. All subscales were then totaled for a combined social-cognitive score. The socio-demographic questionnaire consisted of questions related to participation in a CFSI, and sought information on participant income level, age, gender, educational level, and civil status.

\section{Statistical analysis}

All statistical analysis was completed in IBM SPSS Statistics 19.0. Participants were separated into one of three groups based on participation in a CFSI (nonparticipant, 1 initiative and $>1$ initiative). Initiatives identified in this study included community or urban gardens, farmers markets, communitysupported agriculture, and food stands. We used Spearman's rho correlations to examine bivariate associations between dietary-related social cognitive constructs, age, fruit and vegetable intake, income level, and educational attainment. Additionally, a multiple regression model was run to predict fruit and vegetable intake, community food

Table 2. Dietary-related Social-Cognitive Factor Definitions

\begin{tabular}{ll}
\hline Measurements & Definition \\
\hline Self-Efficacy & Ability to choose health foods when the opportunity was presented. \\
\hline Intention & Intention to adopt healthy eating behavior. \\
\hline Situation & The participant's recollection of food available within the home. \\
\hline Behavioral Strategies & How often the participant incorporates strategies to encourage healthy eating. \\
\hline Social Support & Support from family and friends to eat healthy. \\
\hline Outcome Expectations & Beliefs regarding the physical and cognitive benefits of healthy eating. \\
\hline Outcome Expectancies & Importance of the outcome expectations for the participant. \\
\hline Social-Cognitive & $\begin{array}{l}\text { Sum of subscales (self-efficacy, intention, situation, behavioral strategies, social support, } \\
\text { outcome expectations, and outcome expectancies.) }\end{array}$ \\
\hline
\end{tabular}

Source: Dewar, Lubans, Morgan, and Plotnikoff (2012). 
security participation, and dietary-related socialcognitive score, controlling for education, income, and age.

\section{Results}

\section{Phase 1}

Our research team interviewed a total of seven representatives of local food initiatives that were active in low-income areas (refer to Table 1). The core categories identified were purpose, challenges, resources, and benefits. Main themes associated with the two core categories, challenges and resources, were government, financial, land access, and education (Figure 1). In this research, challenges were not necessarily the contrary of resources, but each was a mediator between the purpose of the CSFI and its outcomes or benefits. Different challenges had to be overcome and certain resources were needed for successful functioning and attainment of the ultimate purpose.

\section{Purpose}

The main purpose of the CFSIs reported by CFSI representatives was to increase the access and availability of fresh produce in areas where fresh produce was limited. Access in this study included making produce affordable to the target population and having fresh produce within the community so people could physically obtain it, even with limited transportation.

\section{Challenges and Resources}

The CFSI representatives identified different challenges and resources associated with reaching their purpose. Subthemes under each category included government, land, education, and financial considerations. Table 3 provides an overview of each of the categories and subthemes.

\section{Benefits}

The representatives of the initiatives identified several benefits of CFSIs. These benefits included: creating a sense of community, promoting overall wellbeing, and increasing access and availability to fresh foods. Coordinators indicated that the projects require contributions from every individual concerned, which unifies the community under one common goal and consequently leads to new and/or stronger relationships between community members. Representatives also reported that initiatives promoted the wellbeing of each participant. Specifically, when someone participated in the

\section{Figure 1. Community Food Security Initiatives}

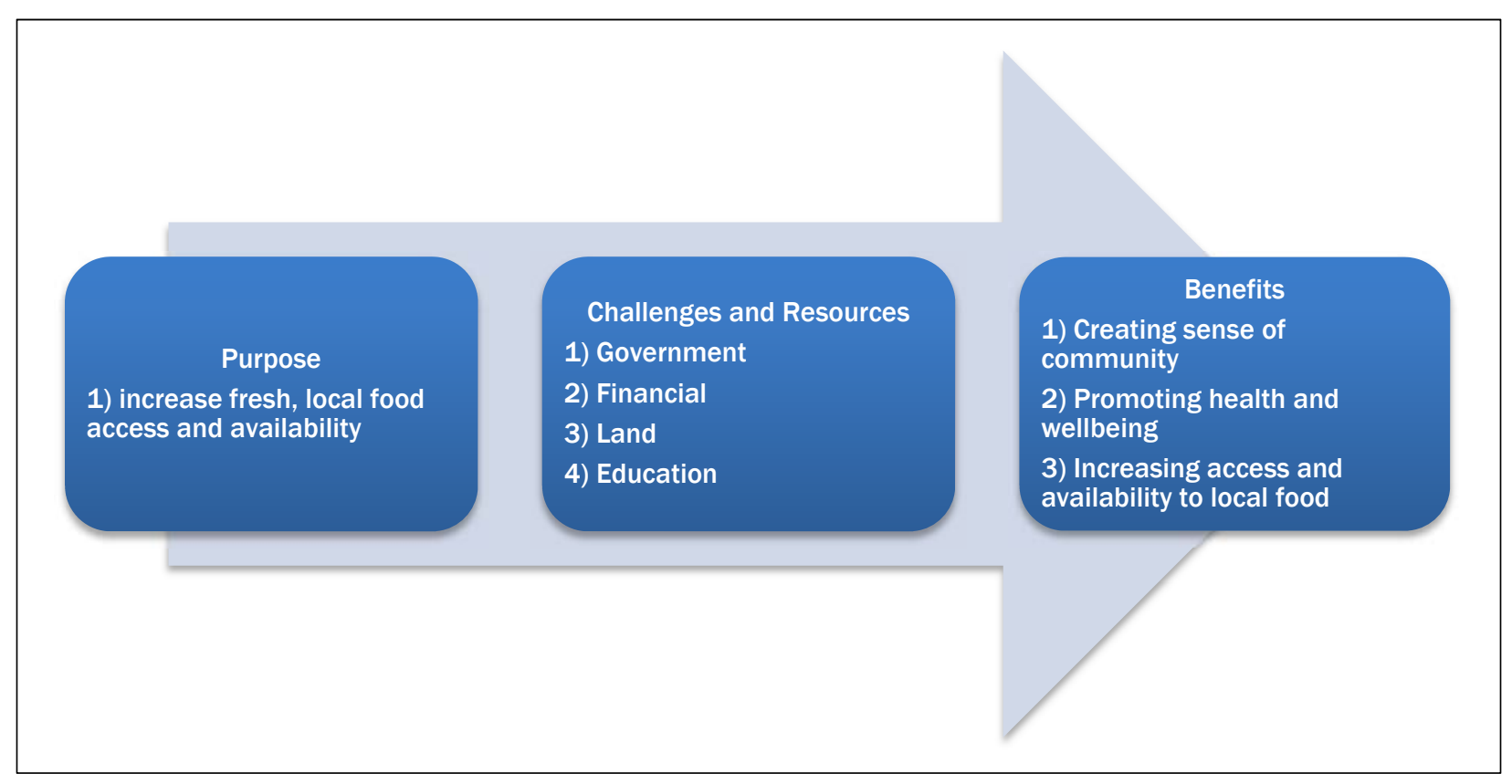


Table 3. Challenges and Resources Identified with a Community Food Security Initiative

\begin{tabular}{|c|c|c|}
\hline & Challenges & Resources \\
\hline Financial & $\begin{array}{l}\text { External funding such as grants, donations, and } \\
\text { governmental programs provide start-up financial } \\
\text { support, but are rarely enough for long-term } \\
\text { success. An initiative must have adequate } \\
\text { customer sales to be sustainable. }\end{array}$ & $\begin{array}{l}\text { Consumer payment convenience has increased due } \\
\text { to technological advancements, such as acceptance } \\
\text { of EBT. Accepting this type of payment has opened } \\
\text { up new markets and opportunities for greater } \\
\text { revenue to initiatives. }\end{array}$ \\
\hline Land & $\begin{array}{l}\text { Depending upon how the city taxes and allocates } \\
\text { the land, its quality can vary. At times, initiatives } \\
\text { are burdened with land that has not been } \\
\text { traditionally used for agriculture. This type of land } \\
\text { usually lacks water and viable soil. }\end{array}$ & $\begin{array}{l}\text { City and government entities can increase quality by } \\
\text { providing water access and compost sources. When } \\
\text { borrowing land from a community member, } \\
\text { squatting, or obtaining it via donation, land can be } \\
\text { cost-effective. Land centralized for consumer } \\
\text { convenience at churches or community centers } \\
\text { increases availability so it can be used for fresh food } \\
\text { production within neighborhoods. }\end{array}$ \\
\hline Government & $\begin{array}{l}\text { Local governments have policies and regulations } \\
\text { regarding compost use, vacant land utilization, } \\
\text { and land taxation. }\end{array}$ & $\begin{array}{l}\text { Local, state, and federal governments provide } \\
\text { training for EBT and options for land use. The } \\
\text { government has also created programs to increase } \\
\text { the available points of purchase of local foods such } \\
\text { as the Senior Citizens and Women, Infants, and } \\
\text { Children Farmers Market voucher programs and EBT } \\
\text { acceptance at farmers markets and through CSAs. }\end{array}$ \\
\hline Education & $\begin{array}{l}\text { The lack of food knowledge relating to production } \\
\text { and preparation can make produce undesirable to } \\
\text { consumers. Knowledge of how to grow food } \\
\text { sustainably is often learned through trial and error } \\
\text { within the programs. There can be a lack of } \\
\text { motivation among the community members to } \\
\text { participate long-term. }\end{array}$ & $\begin{array}{l}\text { Workshops, demonstrations, and nutrition classes } \\
\text { can increase consumer knowledge and cooking skill. } \\
\text { Producers communicate with each other to help } \\
\text { educate on successful growing techniques. }\end{array}$ \\
\hline
\end{tabular}

Table 4. Socio-Demographics of Residents Among CFSI Participation

\begin{tabular}{|c|c|c|c|}
\hline Variables & All & $\begin{array}{l}\text { Membership } \\
\text { in a CFSI }\end{array}$ & No Membership \\
\hline \multicolumn{4}{|l|}{ Education } \\
\hline High school diploma or less & $29(23 \%)$ & $20(69 \%)$ & $9(31 \%)$ \\
\hline $\begin{array}{l}\text { Greater than high school } \\
\text { diploma }\end{array}$ & $99(77 \%)$ & $59(60 \%)$ & $40(40 \%)$ \\
\hline \multicolumn{4}{|l|}{ Household Income } \\
\hline$<$ US $\$ 25,000$ & $55(43 \%)$ & 28 (51\%) & 27 (49\%) \\
\hline$>$ US $\$ 25,000$ & $73(57 \%)$ & $51(70 \%)$ & 22 (30\%) \\
\hline \multicolumn{4}{|l|}{ Gender } \\
\hline Male & $36(30 \%)$ & $25(69 \%)$ & $11(31 \%)$ \\
\hline Female & $86(70 \%)$ & $48(56 \%)$ & $38(44 \%)$ \\
\hline
\end{tabular}

Phase 2

A total of 128 residents from the targeted zip codes completed the socio-demographic survey, the SCDQ, and the QFS (Tables 4 and 5).

Bivariate correlations were examined for educational attainment, education, age, fruit and vegetable intake, and for each of the dietary-related socialcognitive factors. Total fruit and vegetable intake was positively associated with initiative, that person was active and social; therefore, a second benefit of the initiatives was that they promoted both the mental and physical health of their members. Finally, the initiatives provided an alternative avenue for accessing fresh produce and for encouraging healthy dietary intake. self-efficacy $(r=.24, p<.01)$, outcome expectancies $(r=.24, p<.01)$, and social-cognitive total $(r=.30$, $p<.01)$. Food initiative participation was positively correlated with intention $(r=.41, p<.01)$, situation $(r=.35, p<.01)$, expectations $(r=.45, p<.01)$, education level $(r=.41, p<.01)$, and household income 
Table 5. Social-Cognitive Dietary Questionnaire Scores and Fruit and Vegetable Intake Among Participation in CFSIs

\begin{tabular}{lccc}
\hline Measurements & $\begin{array}{c}\text { Involved in } \mathbf{1} \text { Food Initiatives } \\
(\mathbf{4 1})\end{array}$ & $\begin{array}{c}\text { Only Farmers Markets/Stands } \\
(\mathbf{4 4})\end{array}$ & $\begin{array}{c}\text { No Involvement } \\
(\mathbf{3 3})\end{array}$ \\
\hline Total Fruit \& Vegetable Intake & $3.56 \pm 1.9$ & $3.31 \pm 2.0$ & $2.70 \pm 2.0$ \\
\hline Self- Efficacy & $3.11 \pm 0.66$ & $3.10 \pm 0.84$ & $3.00 \pm 0.86$ \\
\hline Intention & $2.79 \pm 0.78$ & $2.37 \pm 0.52$ & $1.94 \pm 0.71$ \\
\hline Situation & $4.27 \pm 0.72$ & $4.11 \pm 0.70$ & $3.38 \pm 1.0$ \\
\hline Behavioral Strategies & $2.39 \pm 0.58$ & $2.43 \pm 0.71$ & $2.21 \pm 0.75$ \\
\hline Social Support & $2.70 \pm 0.62$ & $2.43 \pm 0.65$ & $2.51 \pm 0.95$ \\
\hline Outcome Expectations & $4.63 \pm 0.50$ & $3.91 \pm 0.60$ & $3.61 \pm 0.88$ \\
\hline Outcome Expectancies & $2.70 \pm 0.50$ & $3.27 \pm 0.62$ & $3.27 \pm 0.71$ \\
\hline Social-Cognitive Total & $3.25 \pm 0.38$ & $3.09 \pm 0.42$ & $2.83 \pm 0.60$ \\
\hline
\end{tabular}

$(r=.32, p<.01)$, but negatively associated with expectancies $(r=.23, p<.01)$. Food initiative participation was not significantly related to fruit and vegetable intake.

The regression model was significant $\left(\mathrm{R}^{2}=.09, \mathrm{~F}(5,115)=2.23 ; p=.05\right)$. Social cognitive total was an independent positive predictor of fruit and vegetable intake controlling for all other factors (Table 6). Participation in a CFSI was not a significant independent predictor.

\section{Discussion}

The metropolitan city used in this research is classified as a food desert, and in 2015 it was ranked the eleventh city in the U.S. for experiencing food hardship (Rosso, 2016). Alternative methods that go beyond public food assistance and address the local food system overall_-such as CFSIs - are beginning to form in different areas of the city to address the issue of low food access. As previously mentioned, a main difference between a CFSI and the local food movement is the focus on addressing food insecurity in low-income communities. The present study identified the challenges that confront local CFSIs, the resources needed to support such initiatives, and the benefits of their implementation. As new initiatives in low-income areas develop, it is important to be aware of the challenges that they will face and find appropriate ways to address them. Here, the CFSI
Table 6. Predictors of Fruit and Vegetable Intake

\begin{tabular}{lccc}
\hline Predictors & $\boldsymbol{B}$ & SE $B$ & $\boldsymbol{B}$ \\
\hline Two or More Food Initiatives & -0.04 & 0.43 & 0.01 \\
\hline Social-Cognitive Total & 0.96 & 0.37 & $0.24 *$ \\
\hline Household Income & -0.04 & 0.12 & -0.04 \\
\hline No Food Initiatives & -0.43 & 0.45 & -0.10 \\
\hline
\end{tabular}

* Significant at $p \leq .05$

representatives indicated the challenge at the structural and social levels. For example, different governmental policies hindered certain agricultural practices and land usage while financial resources to encourage initiatives' growth and expansion were minimal at both the public and private levels. Another challenge centered on the lack of nutrition education and motivation to participate long-term within the target communities.

Critics of CFSIs argue that the initiatives need to create both community empowerment to address their own local food issues and the ways to address them (Mares \& Alkon, 2011). In the present study, the key informant interviewees were not of the target community but were coming from the outside into the community. During the interviews, they mentioned the lack of target community involvement and motivation within the initiatives. The lack of community representation in the decision-making process and leadership of the CFSIs may be a reason for this. Therefore, the 
CFSIs in this study may need to explore ways to provide control and empowerment to the local community in addition to bringing people from different sectors (public, civic, religious, and private) together to examine and address local foodsystem issues. Internationally, Via Campesina, a food sovereignty movement, gives the right and power to the local people to define and determine their food systems. CFSIs could adopt aspects of such movements to promote community empowerment by changing the local food system, addressing food insecurity, and promoting a healthy diet.

Along these lines, this study further explored the complexity of dietary habits. Much research has focused on food deserts and the lack of fruit and vegetable availability leading to a decrease in their consumption. However, when promoting fruit and vegetable consumption in low-income populations, other factors beyond food access need to be targeted. Although CFSIs may be increasing the accessibility of local, fresh foods in low-income populations, other factors must be addressed and cannot be ignored when increasing actual intake of these foods. Dietary-related social-cognitive factors predicted fruit and vegetable consumption but not CFSI participation. This coincides with past research mentioned previously. Ver Ploeg and Rahkovsky (2016) reviewed current literature targeting food store access and dietary quality and concluded, "Access alone is not enough. Product prices, income available to spend on food, consumer knowledge about nutrition, and food preferences are perhaps more important determinants of what foods consumers choose to purchase" (p. 23). Therefore, there may be limitations to focusing only on food access in promoting dietary change. The challenge for CFSIs whose purpose is to promote healthy dietary intake, and therefore health, in community members is to examine the ways in which they are functioning and determine where changes need to be made to ultimately achieve their mission. Based on this study and prior studies, the following are reflection questions for CFSIs:

1. Does the community have decisionmaking power within the CFSI? If so, how much and to what degree? If not, how can this be facilitated?

2. Is the leadership team constructed of local community members who have trust within the community?

3. Does the initiative go beyond providing food access to encourage healthy dietary intake and decrease food insecurity?

4. Does the CFSI include culturally appropriate nutrition interventions that encourage healthy dietary habits. Did community members have a central voice in the development and implementation of the interventions? ?

5. Are different sectors (e.g., political, civil, religious, and private) from the community working together to empower and strengthen the CFSI?

There are several limitations to the present study. First, in qualitative research, data saturation is commonly utilized to determine sample. However, due to the limited scope of this study and the geographical area, data saturation was not employed. The recruited sample was made up of residents of the target zip codes who agreed to participate. Further, the results of this study are not generalizable onto a larger population, as convenient sampling methods were utilized to recruit community participants. Therefore, the results cannot conclude causation, but instead point toward the presence of additional factors such as social-cognitive factors that are important to address within CFSIs when their objectives go beyond food access and target healthy dietary intake.

In conclusion, addressing healthy food intake in low-income populations is complex. Although increasing healthy food access is crucial, the psychosocial aspects that influence intake cannot be overlooked. Therefore, as CFSIs continue to develop in low-income areas, it is necessary to include and empower community members to have a voice within the initiatives' processes. Also, interventions addressing the psychosocial factors around food consumption should be tailored to the target population. On the local level, community members, policymakers, healthcare professionals, 
financial investors, and community organizations need to work collaboratively to provide initiatives that are multifaceted and empower the local community as decision makers. Future research examining power structures within the CFSIs and their effect on community wellbeing can provide further insight into their effectiveness beyond food access.

\section{References}

Aggarwal, A., Monsivais, P., Cook, A. J., \& Drewnowski, A. (2014). Positive attitude toward healthy eating predicts higher diet quality at all cost levels of supermarkets. Journal of the Academy of Nutrition \& Dietetics, 114(2), 266-272. http://dx.doi.org/10.1016/i.jand.2013.06.006

Budzynska, K., West, P., Savoy-Moore, R., Lindsey, D., Winter, M., \& Newby, P. K. (2013). A food desert in Detroit: Associations with food shopping and eating behaviours, dietary intakes and obesity. Public Health Nutrition, 16(12), 2114-2123. http://dx.doi.org/10.1017/S1368980013000967

Caspi, C. E., Kawachi, I., Subramanian, S.V., Adamkiewicz, G., \& Sorensen, G. (2012). The relationship between diet and perceived and objective access to supermarkets among lowincome housing residents. Social Science \& Medicine, 75(7), 1254-1262. http://dx.doi.org/10.1016/j.socscimed.2012.05.014

Caswell, J. L., \& Yaktine, A. L. (Eds.). (2013). Supplemental Nutrition Assistance Program: Examining the evidence to define benefit adequacy. Washington, D.C.: National Academies Press.

Colasanti, K. J. A., Conner, D. S., \& Smalley, S. B. (2010). Understanding barriers to farmers' market patronage in Michigan: Perspectives from marginalized populations. Journal of Hunger and Environmental Nutrition, 5(3), 316-338. http://dx.doi.org/10.1080/19320248.2010.504097

Cummins, S., Flint, E., \& Matthews, S. A. (2014). New neighborhood grocery store increased awareness of food access but did not alter dietary habits or obesity. Health Affairs, 33(2), 283-291. http://dx.doi.org/10.1377/hlthaff.2013.0512

Dewar, D. L., Lubans, D. R., Morgan, P. J., \& Plotnikoff, R. C. (2012). Development and evaluation of social cognitive measures related to adolescent physical activity. Journal of Physical Activity and Health, 10(4), 544-555. http://dx.doi.org/10.1186/1479-5868-9-36
Dubowitz, T., Cohen, D. A., Huang, C. Y., Beckman, R. A., \& Collins, R. L. (2015). Using a grocery list is associated with a healthier diet and lower BMI among very high-risk adults. Journal of Nutrition Education and Behavior, 47(3), 259-264. http://dx.doi.org/10.1016/j.jneb.2015.01.005

Dubowitz, T., Zenk, S. N., Ghosh-Dastidar, B., Cohen, D. A., Beckman, R., Hunter, G., \& Collins, R. L. (2015). Healthy food access for urban food desert residents: Examination of the food environment, food purchasing practices, diet and BMI. Public Health Nutrition, 18(12), 2220-2230. http://dx.doi.org/10.1017/S1368980014002742

Flórez, K. R., Dubowitz, T., Ghosh-Dastidar, M., Beckman, R., \& Collins, R. L. (2015). Associations between depressive symptomatology, diet, and body mass index among participants in the Supplemental Nutrition Assistance Program. Journal of the Academy of Nutrition \& Dietetics, 115(7), 11021108. http://dx.doi.org/10.1016/i.jand.2015.01.001

Hackett, A., Boddy, L., Boothby, J., Dummer, T. J. B., Johnson, B., \& Stratton, G. (2008). Mapping dietary habits may provide clues about the factors that determine food choice. Journal of Human Nutrition \& Dietetics, 21(5), 428-437. https://doi.org/10.1111/ j.1365-277X.2008.00894.x

Hoepfl, M. (1997). Choosing qualitative research: A primer for technology education researchers. Journal of Technology Education, 9(1), 47-63. https://doi.org/10.21061/jte.v9i1.a.4

Kaiser, M. L. (2011). Food security: An ecological-social analysis to promote social development. Journal of Community Practice, 19(1), 62-79. https://doi.org/10.1080/10705422.2011.550261

Leung, C. W., Ding, E. L., Catalano, P. J., Villamor, E., Rimm, E. B., \& Willett, W. C. (2012). Dietary intake and dietary quality of low-income adults in the supplemental nutrition assistance program. The American Journal of Clinical Nutrition, 96(5), 977-988. http://dx.doi.org/10.3945/ajcn.112.040014

Low, S. A., Aaron, A., Beaulieu, E., Key, N., Martinez, S., Melton, A...\& Jablonski, B. B. R. (2015). Trends in U.S. local and regional food systems (Administration Publication No. AP-068). Washington, D.C.: U.S. Department of Agriculture, Economic Research Service. Retrieved from http://www.ers.usda.gov/ publications/pub-details/?pubid $=42807$ 
Mares, T. M., \& Alkon, A. H. (2011). Mapping the food movement: Addressing inequality and neoliberalism. Environment and Society: Advances in Research, 2, 68-86. http://dx.doi.org/10.3167/ares.2011.020105

National Cancer Institute. (2013, October 18). Fruit and vegetable screeners in the Eating at America's Table study (EATS): Instruments. Retrieved from http://appliedresearch.cancer.gov/diet/screeners/ fruitveg/instrument.html

Ogden, C. L., Carroll, M. D., Kit, B. K., \& Flegal, K. M. (2014). Prevalence of childhood and adult obesity in the United States, 2011-2012. Journal of the American Medical Association 311(8), 806-814. http://dx.doi.org/10.1001/jama.2014.732

Pearson, T., Russell, J., Campbell, M. J., \& Barker, M. E. (2005). Do "food deserts" influence fruit and vegetable consumption? - A cross-sectional study. Appetite, 45(2), 195-197. http://dx.doi.org/10.1016/j.appet.2005.04.003

Racine, E. F., Mumford, E. A., Laditka, S. B., \& Lowe, A. E. (2013). Understanding characteristics of families who buy local produce. Journal of Nutrition Education and Behavior, 45(1), 30-38. http://dx.doi.org/10.1016/i.jneb.2012.04.011

Rosso, R. (2016). How bungry is America? FR AC's national, state, and local index of food hardship: June 2016. Washington, D.C.: Food Research and Action
Center. Retrieved from http://frac.org/reportsand-resources/

Thompson, F. E., Subar, A. F., Smith, A. F., Midthune, D., Radimer, K. L., Kahle, L. L., \& Kipnis, V. (2002). Fruit and vegetable assessment:

Performance of 2 new short instruments and a food frequency questionnaire. Journal of the American Dietetic Association, 102(12), 1764-1772. http://dx.doi.org/10.1016/S0002-8223(02)90379-2

U.S. Census Bureau. (2016). Dayton City, Obio. Quickfacts. Retrieved on June 15, 2016, from http://www.census.gov/quickfacts/map/PST0452 $\underline{14 / 3921000}$

U.S. Department of Agriculture, Food and Nutrition Service [USDA FNS]. (2015). SNAP benefit redemptions through farmers and farmers markets show sharp increase (Press Release No. 0007-15). Washington, D.C.: Retrieved from http://www.fns.usda.gov/pressrelease/2015/ fns-0007-15

Ver Ploeg, M., \& Rahkovsky, I. (2016, May 2). Recent evidence on the effects of food store access on food choice and diet quality. Amber $W$ aves. Washington, D.C.: USDA Economic Research Service. Retrieved from http://www.ers.usda.gov/ amber-waves $/ 2016 / \mathrm{may} /$ recent-evidence-on-theeffects-of-food-store-access-on-food-choice-anddiet-quality/ 